\title{
VIRTUAL RECONSTRUCTION IN BIM TECHNOLOGY AND DIGITAL INVENTORIES OF HERITAGE
}

\author{
L. Agustín ${ }^{1}$, M. Quintilla ${ }^{1}$ \\ ${ }^{1}$ University of Zaragoza, Predepartamental Architecture Unit, 50018 Zaragoza, Spain - (lagustin@ unizar.es, mquintilla@unizar.es)
}

\author{
Commission II, WG II/8
}

KEY WORDS: Cultural heritage, Web platforms, HBIM, Information systems, 3D models, Inventories

\begin{abstract}
:
The documentation of the architectural heritage requires the storage of large amounts of information that must be stored and processed in very different formats, since it comes from experts from different areas of knowledge. This heterogeneity of information makes communication difficult among professionals who participate in documentation work, such as restorers, architects, engineers, archaeologists or historians, with the transfer of information being one of the biggest problems to be solved, through the creation of a methodology that favors the diffusion and accessibility to the materials coming from the investigation. The aim of the study is to create a protocol or methodology, to create a graphic database that allows the inventory of the architectural heritage in Aragon. The solution implies the development of a geometric model that allows to include and relate information related to it. The format is a HBIM model capable of incorporating information on a stratified support, with visualization, documentation and management capabilities that allow a complete view of the building to be cataloged, incorporating useful information for its conservation, restoration, protection and dissemination, as well as interoperability between tools and other systems throughout the entire life cycle of the object. In this research, we will work with the virtual platform Petrobim, a tool composed of a database and a viewer, whose purpose is the management and query of information linked to a 3D model, throughout the entire cycle building life.
\end{abstract}

\section{INTRODUCTION}

\subsection{General introduction}

The graphic documentation of the architectural heritage constitutes one of the most powerful tools for the preservation and diffusion of its cultural and material values. All of them must be duly registered to be preserved, which is achieved with an adequate graphic documentation, basis for research, protection, conservation and dissemination (Gómez, 2013). The documentation of architectural heritage requires the storage of large amounts of information that must be stored and processed in very different formats, as it comes from experts from different areas of knowledge. This heterogeneity of information makes communication difficult among professionals who participate in documentation work, such as restorers, architects, engineers, archaeologists or historians, with the transfer of information being one of the biggest problems to be solved, through the creation of a methodology that favors the diffusion and accessibility to the materials coming from the investigation. Another disadvantage of traditional work method is the limited transmission of information between different entities, not only among researchers or administrations, nor does it favor dissemination among the general public (Finat et al, 2010).

Traditionally, the information contained in the architectural catalogs had a 2D format, composed of plans, photographs and texts. But with the evolution of representation systems, their progress has been linked to computer development. There are so many advantages obtained that currently the restoration of heritage assets implies the mandatory realization of a 3D model, which will allow to dump data from the investigation. This leads to new challenges, such as the storage of information and its accessibility in a simple and intuitive way thanks to the use of a 3D web platform. The electronic dissemination of information is considered a solution that responds to most of the problems mentioned, since it allows a permanent update, flexibility, ability to introduce any type of support, selective distribution, interaction with the user and lower costs of production. The knowledge must be able to be stored, processed and analyzed on a common support that allows to contain all the available materials of a patrimonial element.

A new approach to the cataloging of architectural heritage is proposed, thanks to the use of technologies that allow storing information in the same model as the HBIM (Historic Building Information Modeling). BIM technology allows to manage and store large amounts of information in different formats: alphanumeric information of technical and scientific data, raster and vector format of plans, maps, images, drawings, etc. That is why, for the complete documentation of the patrimony and to be able to have exhaustive and useful inventories for all the contemplated uses, it provides the required functionalities.

\subsection{State of the art}

The activities related to the documentation of heritage require collaboration between different disciplines and technologies, making it necessary to share the information in an orderly manner and which in turn is available at any time (Fassi et al., 2015). Currently, the web is the place of consultation for all those who seek knowledge or content. By representing the model with different levels of detail (LoD), it allows to provide a fluid visualization and an efficient access to the data, also reducing the latency time and the compression (Scopigno et al. 2017). The BIM information systems are capable of integrating all types of information and documentation, as can be seen in numerous examples (Oreni et al., 2014, Nieto et al., 2016) but its ability to interconnect with the web, and in this way resolve the needs for interoperability and accessibility, gives it greater qualities for its use in the management and dissemination of heritage. 
In recent years, research has focused on how to share 3D models through the web, creating online information systems. One of the first programs developed for the online visualization of heritage is NUBES, an open source web platform for storing, manipulating, consulting and managing data on heritage buildings, focused on its subsequent restoration (Stefani et al. 2014). The polygonal model of the building is divided into smaller sub-elements, organized under a semantic structure. To each element it is incorporated two-dimensional layers with information and insertion points on the specific $3 \mathrm{D}$ model to link to complementary information.

BIM3DSG is an integrated system that allows you to import a complex 3D model to a web platform. Through it, it allows to access all the information stored in a BIM model, totally or partially, through the constitution of entities defined by the user, allowing to choose their visualization among seven levels of detail. In addition, the system offers the possibility of adding information and files associated with the different objects that make up the model, such as images, videos, documents or CAD files. Being a web platform, there are no additional costs and allows mobility and viewing on mobile devices. One of the key aspects is that all the functionalities are available to work online. The application could be used during the restoration work of the Duomo in Milan (Rechichi et al., 2016) or for the conservation of the mosaics of San Marco in Venice (Fassi et al., 2017).

The use of semantic models in web platforms focused on the dissemination of heritage allow a more effective use of resources and greater speed of visualization (Apollonio et al., 2011). That is why the latest research in the field of HBIM web platforms focuses on the use of open Semantic Web technologies, to solve interoperability problems between 3D models and associated software. Through the use of semantic web standards, such as IFC / OWL (standard for BIM modeling in a semantic web language), it is possible to share the information stored in a HBIM model to be accessible for consultation through a web platform. At the same time, the agreed standards for the cataloging and ordering of the built heritage information guarantee the compatibility between the databases and facilitate the registration and exchange of information. In the context of cultural heritage, the main ontology used for the management of documentation is CIDOC-CRM "CIDOC Conceptual Reference Model", which is compatible with other vocabularies such as the Art and Architecture (AAT) tesaruro prepared by the Getty Institute.

We find examples, such as BIMexplorer tool, a web platform whose purpose is the visualization of results and the realization of semantic queries to the model, to non-expert users. Complete interoperability of data from a standard HBIM is guaranteed through the use of the IFC / RDF format (Quattrini et al. 2017). Another case is the INCEPTION project, which focuses on the integration of semantic attributes with 3D models created under a semantic structure, to manage patrimonial information. To this end, a web platform has been created that allows accessing the information stored in a semantic HBIM model and interacting with it, allowing additional information and documentation to be added to the entire building or geometric element, and to perform spatial and multi-criteria queries. In addition, a glossary has been integrated into the platform that uses the AAT treasury of the Getty Institute, to cover all the nomenclatures of the heritage that BIM programs do not possess. This use of ontologies is what favors the exchange of information. It should be added that the use of the W3C OWL-
Time ontology allows to represent different temporal phases. These characteristics give the platform great versatility to be used for multiple purposes, such as conservation, restoration or dissemination, since it allows adapting as the information is displayed according to the user (Iadanza et al., 2019).

In this aspect this technology is interesting for the creation of architectural catalogs that having an information organized under the same 3D model, allows through a management system, to manage the diversity of contents and functionalities generated by the different specialists involved in conservation, protection, restoration and dissemination of heritage.

\subsection{Objectives}

The aim of the study is to create a protocol or methodology, to create a graphic database that allows the inventory of the architectural heritage in Aragon. The present article tries to solve this situation, by means of the sample of a case of study: the Joint of the City council and Lonja de Alcañiz (Teruel), declared Good of Cultural Interest. The solution implies the development of a geometric model that allows to include and relate information related to it. The format is a HBIM model capable of incorporating information on a stratified support, with visualization, documentation and management capabilities that allow a complete view of the building to be cataloged, incorporating useful information for its conservation, restoration, protection and dissemination, as well as interoperability between tools and other systems throughout the entire life cycle of the object. In this research, we will work with the virtual platform Petrobim, for the management of archaeological-architectural heritage in conservation and restoration processes.

You want to check if the platform is suitable for the management of information aimed at obtaining a heritage catalog, for this it is considered that the basic characteristics that must be fulfilled are (Myers, 2016):

- $\quad$ Let it be a high resolution 3D graphic model, divided under a semantic structure. The model must be able to incorporate any type of information and format that can be distributed selectively.

- It must be a geo-referenced database.

- It should generate a flexible database that allows the introduction of data according to any demand of the different disciplines or activities derived from the study and protection of heritage, with the possibility of including all types of media.

- The dissemination platform must be open source, standardized and accessible through a web environment.

- The information must be standardized, integrating international standards of inventory and documentation of heritage to perform a useful management of all data generated and implemented by all disciplines intervening in the heritage.

\section{PETROBIM}

PetroBIM is a tool composed of a database and a viewer, whose purpose is the management and consultation of information linked to a 3D model, throughout the life cycle of the building. It allows the exchange of historical heritage information regarding conservation and restoration projects, among the different collaborators through a geometric model that 
integrates all types of information and is capable of carrying out operations in real time (Armisén et al., 2016).

\subsection{Components}

The platform is composed of three elements: a geometric model, server and viewer, accessible through an internet browser or as a desktop application:

- $\quad$ Geometric model: The 3D model must be imported in .fbx format to the platform. This can be generated by any type of modeling software and the level of detail desired depending on its final use. It makes it possible to link all kinds of attributes linked to the model, which will be accessible through different modules.

- Server: Both the 3D model and the associated metadata are stored on a remote server (cloud), responsible for carrying out connection operations between the data consulted and the viewer.

- Viewer: It is formed by the 3D visualization system and the consultation and edition panel.

\subsection{Operability}

The 3D model integrates all types of data (attributes), thanks to a database that incorporates preloaded information regarding materials, pathologies, historical phases ... characteristic of restoration and conservation projects, but leaving the possibility of introducing new concepts. The input of data to the different elements in which the model has been divided according to the desired level of detail, is done through the menu "Commands and Modules". The system makes it possible to temporarily delimit the information by creating "campaigns", allowing the information to be entered individually and in this way to make comparative consultations between campaigns. At any time you can perform simple or multiple searches in several modules simultaneously, whose results can be exported in .png and .dxf formats.

The program has numerous tools to operate with the model, especially, it facilitates the navigation and realization of graphic and numerical consultations, applying selective filters since when working in a network, the information is updated in real time and is accessible and centralized. CAD tools allow measurements of distances, areas or volume on the 3D model or on any search result, and drawing tools allow you to create lines or surfaces on it. The equipment and sensors tool stands out, fundamental for the humidity and deformation modules, where the position in the model of the data-loggers and associated sensors is determined. You can incorporate parameters, as well as an .xls file with data obtained over time. The way to operate the different tools is through different specific modules for conservation and restoration work.

\subsection{Description of modules}

Next, the different available modules for the introduction of data to the web platform are described:

- 3D Modeling: Responsible for supplying the geometric model to the server and the rest of the work modules. The 3D model in .fbx format is incorporated into the platform already defined according to the level of detail required in each project.

- Constructive elements: The 3D model divided according to a semantic structure makes it possible to differentiate the constructive elements, according to an ontology.
- Constructive materials: The module is conceived for the introduction of information from previous study phases (archaeologists, historians) and define information regarding construction materials and their attributes (physical properties, finish, porosity, density ...), in order to be able to be subsequently used for both restoration and dissemination.

- Alteration: The pathologies or degrees of alteration present in the model are defined (efflorescence, sandification, patinas ...) that allow determining the state of deterioration and its future intervention. The module has a database with the terms defined by ICOMOS and the Ministry of Culture of Spain (COREMANS).

- Constructive phases: It allows to assign to the model temporary or constructive attributes for the realization of graphic or numerical queries that can be visualized by means of animations (Eg: temporary or constructive sequences).

- Humidity: Specific module for pathologies related to humidity, with monitoring and analysis capacity. Including the possibility of defining attributes to a certain parameter as a function of time.

- Deformation: Definition of topographic-structural attributes for the supervision of structural problems.

- Intervention: Based on the information available in the previous modules, allows the drafting of restoration projects by assigning a certain action in response to a pathology.

- Maintenance: Module oriented to the tasks of management and maintenance throughout the life cycle of the well documented once the restorationconservation process is finished.

\section{CASE STUDY: TOWN HALL AND LONJA OF ALCAÑIZ (TERUEL)}

As in any virtual study of heritage, it is necessary the practical application on a real model, where you can experience the research carried out, in this case it will be applied to the buildings that currently form the Town Hall Complex and the Lonja of Alcañiz (Teruel).

The set "Town Hall and Lonja" of Alcañiz was declared historic-artistic monument, by decree of the Ministry of Public Instruction and Fine Arts of June 3, 1931, (published in the Gaceta de Madrid of June 4, 1931). Currently, Asset of Cultural Interest, Monument category. Published in the Official Gazette of Aragón of April 16, 2004 (Thomson, 2015).

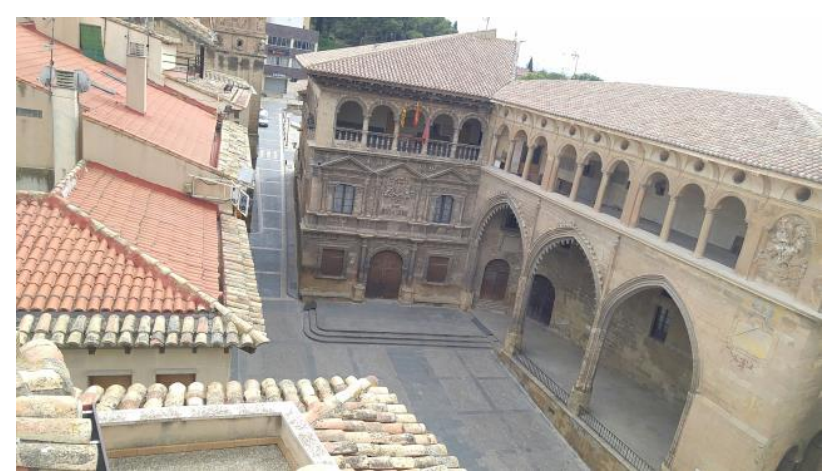

Figure 1. Exterior from the Town Hall of Alcañiz (Teruel) 
The set of both buildings takes a monumental and structurally compositional unit despite the difference of artistic styles (Fig. 1), the Lonja of clearly Gothic and the Town Hall of Renaissance style, based on the archaeological works of Fco. Javier Gutiérrez and his archaeological tastings there is a certain temporal unity in the foundations of both buildings, moreover, there are samples of what could have been a beginning of foundations that would locate the arcades of the auction of Alcañiz, with an orthogonal layout to the facade of the town hall, theoretically older, but would give explanation to the angle of $\mathrm{XX}^{\mathrm{o}}$ that form both facades, with a conception of space influenced by the geometry of the perspective, characteristic of many public spaces of Renaissance style against geometry perpendicularity totally assumed in the Gothic style.

The building of the Lonja, in front of the conception of the great gothic lonjas of the Crown of Aragon (Palma, Valencia, Barcelona or Perpignan) (Thomson, 2015) it is not a closed building but an open loggia, like the Italian lodges of the time, which would reinforce the idea of being Gothic despite being moved or built outside of its Gothic period, consisting of two floors one low where it would generate a large open space built with 3 large pointed arches and an upper floor, where there is a gallery that connects with the Town Hall building. The Town Hall, of clear Italian influence with its faceted façade on three floors, in the style of the classical Aragonese palaces, with a ground floor, with patio and service quarters, a monumental staircase, following the Aragonese compositional tradition, a noble or main floor and culminated with a plant generating a gallery, with continuous arcades that links with the building of the Lonja.

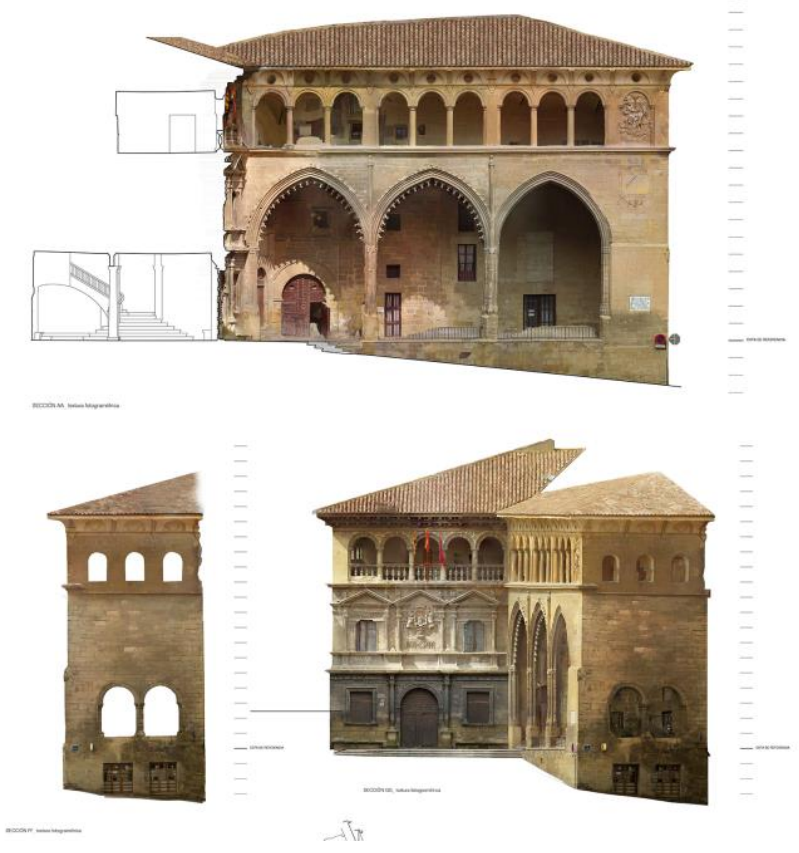

Figure 2. Photogrammetric texture of the facades and gallery of the Town Hall of Alcañiz (Teruel)

The work is structured in two phases: the capture of data from the outside of the current state of the building for the creation of the 3D model, and its subsequent incorporation into the Petrobim web platform. In the BIM model, all types of data from the investigation of any of the agents involved will be downloaded. It will allow to organize in the model information of the constructive systems, physical characteristics of the elements, the historical evolution and detected pathologies, at the same time that there will be a graphic representation faithful to the reality of the real form of the historical building (Fig. 2). The model will allow interoperability between the disciplines involved in the Heritage, avoiding duplication of information and being accessible at all times to all involved.

\subsection{The survey and the model construction}

The team to carry out the research work is multidisciplinary, consisting of an archaeologist, a historian, a company that carries out a geophysical study, by means of geo-radar, a surveying company and part of the members of the GIA group (Group of Research in Architecture) of which the speakers are part.

\subsubsection{Data collection}

The objective is to obtain a dense cloud of points that collects the geometry of both buildings, from the points that will characterize the cloud you will get 6 coordinates, the first 3 of position $\mathrm{X}, \mathrm{Y}, \mathrm{Z}$ and 3 more to characterize the color coordinates R, G, B. To obtain these clouds of points two campaigns were carried out in two consecutive weeks and photogrammetry and laser scanner techniques were used.

For the photogrammetry, collections of proximity photos were used using terrestrial photogrammetry criteria, made with a Nikon F-810 camera and a wide angle of $17 \mathrm{~mm}$. $\left(104^{\circ}\right)$ and 24 $\mathrm{mm}$. $\left(83^{\circ}\right)$, collections of photographs using terrestrial photogrammetry criteria were also used, for which a Dronn Phantom 3 was used, with a 12 megapixel camera and automatic stabilizer, as well as GPS that geolocates each one of the photographs taken. With the different sets of photographs and using the software Photoscan, the first clouds of points have been made, which aligning and combining has allowed us to have a first mesh and approximation to the geometry of the building.

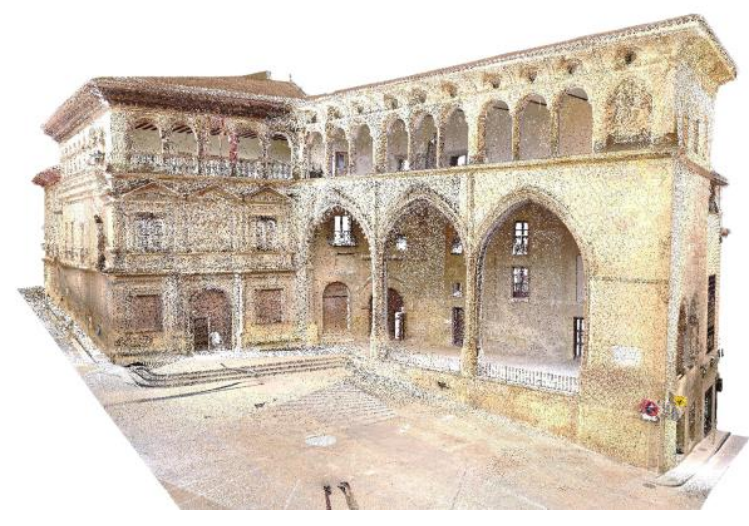

Figure 3. Point cloud obtained by photogrammetry and drone of the Town Hall of Alcañiz (Teruel)

In order to accurately position the point clouds and eliminate the uncertainty of the dimensional error, which can cause the use of photogrammetry, the architectural unit was scanned with a laser scanner of the Faro brand, model Focus 150, with the different point clouds lined up and formed a cloud that overlapped with the one obtained through photogrammetry in 
Autodesk's Recap software (Fig. 3). Once the data capture and generation of the model has been done, the next step is the incorporation of the model to the platform for online viewing.

\subsubsection{Construction of the semantic model}

The platform allows the incorporation of any type of geometric model, whether it comes from modeling software such as 3D Studio Max, Rhinoceros ..., or a mesh from a dense cloud of points. Despite these options, from the beginning it is appreciated that the program is designed to work with the first option. When importing the model already divided into components, it facilitates its selection and assignment of features, such as constructive or material elements. However, for the case study, we decided to import a mesh model, since there was not enough time to model in detail. Once the 3D model of the building is obtained, the first step in the workflow is the division of the model under a semantic structure, which allows to organize the information in an orderly manner and at the end of the process to be able to access it easily for consultation. To do this, a taxonomy is assigned to each construction element according to its level of hierarchical organization. For this, the model obtained from Photoscan was imported into the open source software Cloud Compare, for the processing of the mesh, allowing to orient and segment the model into components, to be later exported in .fbx format to Petrobim (Fig. 4).

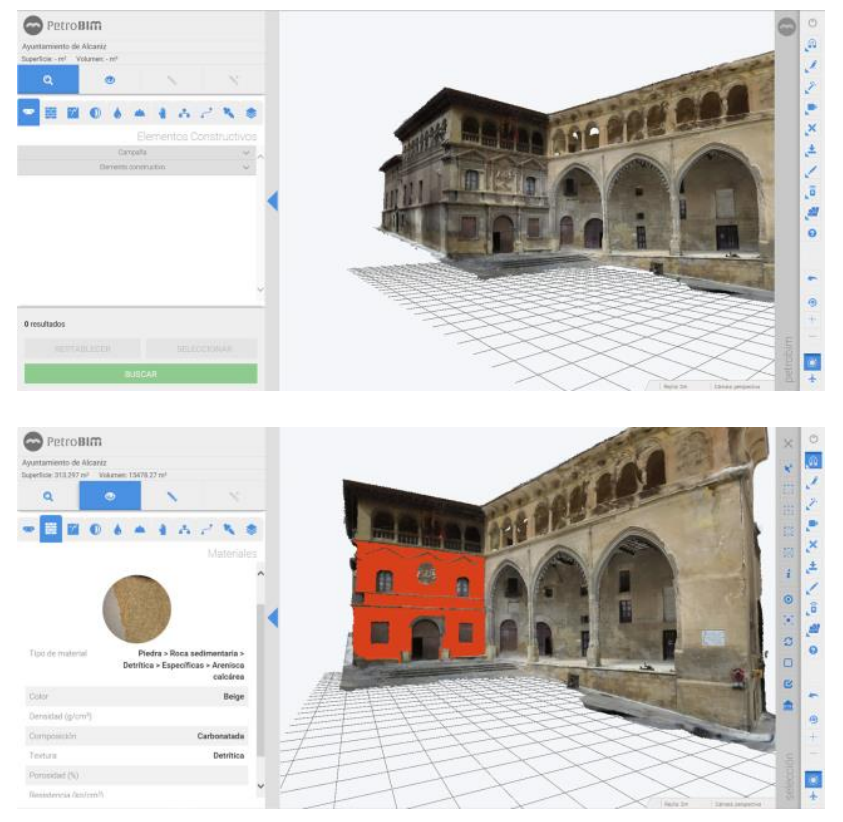

Figure 4. Web platform Petrobim with the model mesh and viewer of the material module of the facade of the masonry factory

\subsection{Operability of the tool}

Once the model was generated and segmented to work properly in Petrobim, the information coming from the archaeological report was introduced prior to the subsequent restoration project. The objective was to know if the platform had the adequate capacities to store all the information that had been generated during the process of intervention in the property by the different professionals involved (Fig. 5).

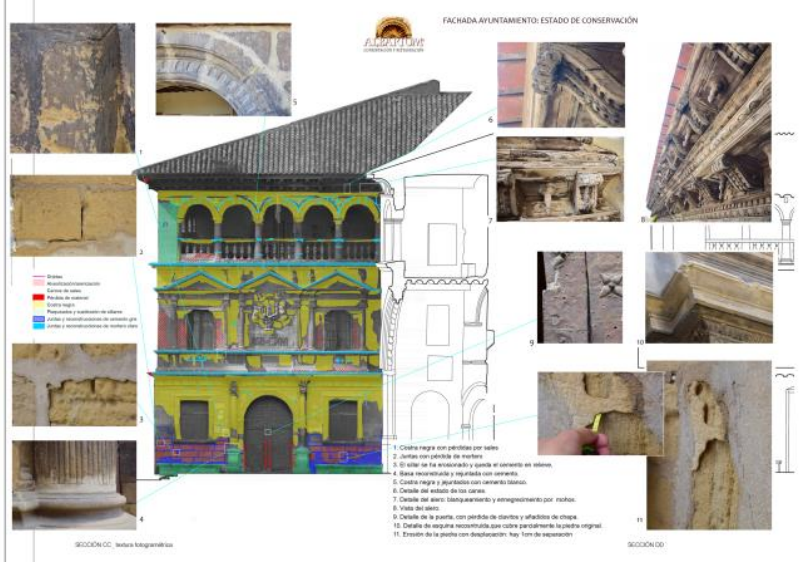

Figure 5. Resultados del informe arqueológico elaborado por Albarium S.L. Conservación y Restauración

In the first place, we proceeded to assign the constructive characteristics to the different parts in which the mesh was previously divided, in order to begin to introduce the information referring to each constructive element. In this way, the different building materials, available in the database, were introduced, being able to choose between a long predefined list, and assigning characteristics such as color, composition, texture, porosity, resistance or humidity. Once the materials were defined, the pathologies exposed in the archaeological reports were assigned, all of them collected in the internal database according to the material and defined according to the terms defined by ICOMOS and COREMANS. This device allows you to define the degrees of alteration and enter photographs of the current state. Based on the information available in the previous modules, the actions to be executed according to each construction element were defined, thus obtaining the affected area and the cost according to the measurement. This intervention module is of great importance to take real control of the costs of execution of the restoration work. Then, in the maintenance module, the maintenance conditions established in the restoration project were introduced, being able to assign periodicity and notification when appropriate to the assigned personnel.

After the process of entering data to the web platform, the ability to analyze the system was verified, by searching for related information between the different modules. The results are displayed on the screen in a simple and easy to understand way, based on the visualization by means of different colors of the results on the model (Fig.6).

\section{DISCUSSION}

The management of all the information generated during the process of conservation and restoration of a building is complicated, since it involves numerous professionals and different formats. Petrobim has been developed to respond to these problems, through the creation of a web platform that unifies all agents and all types of documentation. It has great benefits, such as being a web platform accessible from any device and place, easy to use and is specific for conservation and restoration work throughout the life cycle. It has different modules aimed at introducing all the necessary data in a restoration project and it is a constantly updated program, since new modules are incorporated as new utilities are needed. 
In our case of study we found some limitations, since we did not have time to elaborate a model with a great level of detail, only being able to work with a textured mesh. When importing the model to the platform we found some problems to select the segments in which we had divided the mesh and assign them the constructive elements. The program is more oriented to work with models from 3D studio max or Rhinoceros, although it allows the introduction of meshes. Another point to note is the database of construction elements. Unlike the other modules, in this case the base is scarce. It is considered interesting that it could incorporate vocabulary like the thesaurus of Art and Architecture (AAT) elaborated by the Getty Institute, although it allows to create new constructive elements, in this way it would facilitate the interoperability with other platforms and between users. In addition, sometimes it is necessary to incorporate a more exhaustive description, missing a field that allows to incorporate this information.

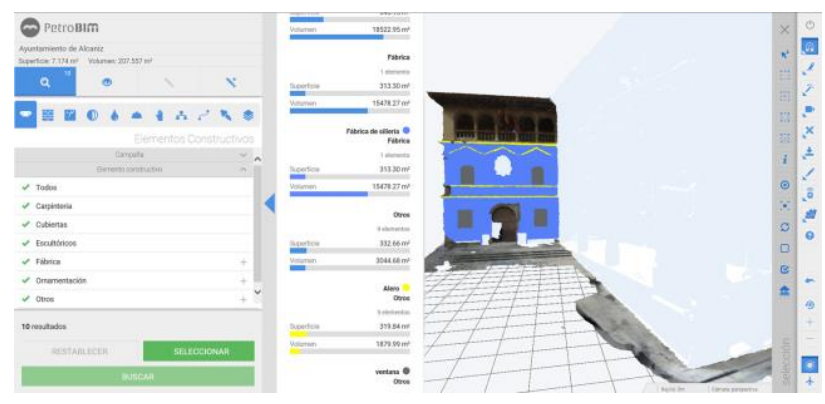

Figure 6. Web platform Petrobim. Results of the search for constructive elements

It is considered to be a great tool for the management of information aimed at the conservation and restoration of heritage, but would need the incorporation of additional modules to be useful for documenting other uses of heritage such as protection or dissemination.

\section{CONCLUSIONS}

The increase in information and the heterogeneity of the formats used in the documentation of the heritage make interoperability between databases and professionals difficult, requiring new storage and administration needs. In recent years there have been numerous experiences aimed at managing and disseminating information on cultural heritage, through the creation of information systems capable of working in a coordinated manner to manage the diversity of contents and functionalities generated by different specialists. involved in the conservation, protection, restoration and dissemination of heritage.

To be able to manage the information, a system is needed to manage in a coordinated way the tools and systems used throughout the life cycle of the asset. Therefore, the main characteristics that a system must possess are interoperability, accessibility, standardization and standardization, as well as the ability to work with high resolution models capable of incorporating any type of information and selectively distributable format. In this regard, the main goodness of the Petrobim platform is the ability to access information in real time through a web environment, key to the decentralized work of heritage professionals. Another additional point is the management of information related to conservation work and restoration of heritage throughout its life cycle, facilitating accessibility to the different disciplines and carrying out selective queries of information to the database.

The latest research on heritage documentation focuses on developing information systems capable of storing and managing information in real time, accessible through web platforms and created under standard technologies that allow interoperability between different databases, prioritizing features as ease of use by non-expert users and the visualization of the model. In turn, they are characterized by using a 3D model built according to a semantic structure on which the information stored in a database is recorded on its surface and accessible for consultation. The system allows professionals to insert information in real time in 2D and 3D formats. The next phase of the study will focus on the use of a system similar to that of GIS tools, incorporating geographic tools, analysis and administration, for the cataloging of Aragonese architectural heritage.

\section{ACKNOWLEDGEMENTS}

To thank the colleagues of the Architectural Graphic Expression Area, Angélica Fernández and Miguel Sancho for their work during the process of data collection and development of the model. This work has been possible thanks to the collaboration agreement signed between the University of Zaragoza and Petrobim. Project funded by the Government of Aragon (T37_17R: Architecture Research Group (GIA)) and co-financed with Feder 2014-2020 "Building Europe from Aragon".

\section{REFERENCES}

Apollonio, F.I., Benedetti, B., Gaiani, M., 2011. Construction, Management and Visualization of 3D Models of Large Archeological and Architectural Sites for E-Heritage GIS Systems, XXIIIrd International CIPA Symposium, Prague, Czech Republic. doi.org/10.6092/unibo/amsacta/3141

Armisén Fernández, A., García Fernández-Jardón, B., Mateos Redondo, F. J., Valdeón Menéndez, L., Rojo Álvarez, A., 2016. Plataforma virtual para el diseño, planificación, control, intervención y mantenimiento en el ámbito de la conservación del patrimonio histórico "PETROBIM". Congreso EuroAmericano REHABEND 2016, Universidad de Cantabria.

Denard, H., 2009. The London Charter for the Computer-Based Visualization of Cultural Heritage. London, UK: King's College London.

Fassi, F., Achille, C., Mandelli, A., Rechichi, F., Parri, S., 2015. A new idea of BIM system for visualization, web sharing and using huge complex $3 \mathrm{~d}$ models for facility management, ISPRS - International Archives of the Photogrammetry, Remote Sensing and Spatial Information Sciences, XL-5/W4, 359-366. doi.org/10.5194/isprsarchives-XL-5-W4-359-2015

Fassi, F., Fregonese, L., Adami, A., Rechichi, F., 2017. BIM system for the conservation and preservation of the mosaics of San Marco in Venice, ISPRS - International Archives of the Photogrammetry, Remote Sensing and Spatial Information Sciences, XLII-2/W5, 229-236. doi.org/ 94/isprs-archivesXLII-2-W5-229-2017 
Gómez González, Ll., 2013. Estudio y adaptación al PNCPCSXX de los inventarios de arquitectura de España. Instituto del Patrimonio Cultural de España, Ministerio de Educación, Cultura y Deporte.

Iadanza, E., Maietti, F., Ziri, A.E., Di Giulio, R., Medici, M., Ferrari, F., Bonsma, P., Turillazzi, B., 2019. Semantic web technologies meet BIM for accessing and understanding cultural heritage, ISPRS - International Archives of the Photogrammetry, Remote Sensing and Spatial Information Sciences, XLII-2/W9, 381-388. doi.org/10.5194/isprs-archivesXLII-2-W9-381-2019

Mateos, F.J., Valdeón, L., Armisén, A., Rojo, A., 2018. Petrobim y la gestión del patrimonio arqueológicoarquitectónico. ATEMPO, X Jornadas de Conservación y Restauración de Bienes Culturales. "Restauradores Satélite". $1,8-25$.

Myers, D. 2016. Heritage inventories: promoting effectiveness as a vital tool for sustainable heritage management. Journal of Cultural Heritage Management and Sustainable Development, 6(2), 102-112. doi.org/10.1108/JCHMSD-02-2016-0009

Nieto Julián, J.E., Moyano Campos, J.J., Rico Delgado, F., Antón García, D., 2016. Management of built heritage via HBIM Project: A case of study of flooring and tiling, Virtual Archaeology Review, 7(14), 1-12. doi.org/ 10.4995/var.2016.4349

Oreni, D., Brumana, R., Della Torre, S., Banfi, F., \& Previtali, M., 2014. Survey turned into HBIM: the restoration and the work involved concerning the Basilica di Collemaggio after the earthquake (L'Aquila). ISPRS Annals of the Photogrammetry, Remote Sensing and Spatial Information Sciences, 2(5), $267-$ 273. doi.org/10.5194/isprsannals-II-5-267-2014

Principios de Sevilla, 2011. International Principles of Virtual Archaeology. Sevilla: INNOVA/SEAV.

Quattrini, R., Pierdicca, R., Morbidoni, C., Malinverni, E.S., 2017. Conservation-oriented HBIM. The bimexplorer web tool, ISPRS - International Archives of the Photogrammetry, Remote Sensing and Spatial Information Sciences, XLII-5/W1, 275281. doi.org/10.5194/isprs-archives-XLII-5-W1-275-2017

Rechichi, F., Mandelli, A., Achille, C., Fassi, F., 2016. Sharing high-resolution models and information on web: the web module of bim3dsg system, ISPRS-International Archives of the Photogrammetry, Remote Sensing and Spatial Information Sciences, XLI-B5, 703-710. doi.org/10.5194/isprs-archivesXLI-B5-703-2016

Scopigno, R., Callieri, M., Dellepiane, M., Ponchio, F., Potenziani, M., 2017. Delivering and using 3D models on the web: are we ready?. Virtual Archaeology Review, 8(17), 1-9. doi.org/10.4995/var.2017.6405

Statham, N., 2019. Scientific Rigour of Online Platforms for 3D Visualization of Heritage, Virtual Archaeology Review, 10(20), 1-16. doi.org/10.4995/var.2019.9715

Stefani, C., Brunetaud, X., Janvier-Badosa, S., Beck, K., De Luca, L., Al-Mukhtar, M., 2014. Developing a toolkit for mapping and displaying stone alteration on a web-based documentation platform, Journal of Cultural Heritage, Elsevier Masson, 15(1), 1-9.

Thomson Llisterri, T., 2015. Conjunto Lonja-Ayuntamiento de Alcañiz. Fuentes y estado de la cuestión, Jornadas de Arte sobre la Lonja de Alcañiz. Taller de investigación multidisciplinar. Jornadas de estudio y difusión del patrimonio. Contextualización histórica. Alcañiz, Centro de Estudios de Arte del Renacimiento, 1 al 3 de julio de 2015.

UNESCO, 1972. Convención sobre la protección del patrimonio mundial, cultural y natural. World Heritage Comitee. 